Chornet Roig, Jaume.

Universidad Politécnica de Valencia.

Gómez Haro, Leonardo.

Universidad Politécnica de Valencia.

\title{
Sobre otras fallas posibles (entre otras utopías).
}

\author{
TIPO DE TRABAJO
}

Comunicación.

PALABRAS CLAVE

Fallas, estructuras efímeras, imágenes simbólicas, sátira, espacio público, fiesta.

KEY WORDS

Fallas, ephemeral structures, symbolic images, satire, public space, folk festivals.

\section{RESUMEN}

Hay otras fallas posibles. Esa era la premisa que nos animó a aceptar la propuesta que llegó a nuestro Departamento de Escultura, desde la Comissió de la Falla Avd. Tarongers-Universitat Politècnica-Camí de Vera, para realizar su falla infantil de 2013. Un encargo asumido, desde nuestro ámbito docente e investigador, como una oportunidad de reflexionar sobre un fenómeno muy desatendido por los estudios en Bellas Artes, y, sin embargo, pensamos, tan estrechamente vinculado a la intervención escultórica en el espacio público, tanto en lo que se refiere a soluciones técnicas relativas a la construcción de estructuras de gran formato, como a cuestiones que atañen a la fiesta, a la colectividad, a las relaciones de unos con otros, y al tipo de imágenes simbólicas del que nos servimos para criticar al poder cuando nos dejan.

\section{ABSTRACT}

Other kind of Fallas are possible. This idea encouraged us to accept the proposal made from Comissió de la Falla Avd. Tarongers-Universitat Politècnica-Camí de Vera to Department of Sculpture, which was to create their children's Falla 2013. That assignment was assumed, from our teaching and researching field, as an opportunity to think about a fact that was absolutely unattended by Fine Arts studies, but however, so close to sculpture in public space, we think. This relationship is not only close in those matters concerning to technical solutions for big sculptures but also in those facts involving folk festivals, community, relationships and the kind of symbols and images we use as soon as we can to criticise power.

\section{CONTENIDO}

Decidimos emprender la búsqueda de otras formas de hacer fallas por entender que, al igual que hay otros mundos posibles, también hay otras posibilidades de plantearse una falla. Ni más ni menos que cuantas seamos capaces de imaginar. Sólo nos impusimos una limitación en nuestra tarea: compaginar tradición e innovación, y utilizar materiales no contaminantes. Dicha exigencia obedecía a una reflexión añadida en torno a la pregunta: ¿qué es una falla? La respuesta más inmediata es que las fallas no son hoy lo mismo que eran hace cien años, y que, por consiguiente, hablamos de una práctica colectiva que, como la sociedad misma de la que pretende ser reflejo, está en continua evolución. De hecho, lo único que sabemos en cuanto a sus orígenes es que ya era costumbre en el siglo XVIII levantar tablados, junto a las fachadas de las casas, sobre los que se plantaban toscas figuras que parecían representar escenas de algún sainete, y a los cuales se prendía fuego la víspera de San José. Y se sabe por documentos de la época que, en un momento dado, las autoridades obligaron a quemar esas estructuras horizontales en los cruces de calles y plazas para evitar incendios, y que tal 
medida provocó, a la larga, que aquellos primitivos tablados pasasen a tener una estructura más vertical, permitiendo la multiplicación de las escenas al poder ser rodeados.

Aparte de esas evidencias, poco más se sabe de cómo se inició dicha tradición, aunque la explicación más extendida la asocia a la costumbre de los carpinteros, al inicio de cada primavera, de sacar a la calle el parot del que colgaban los candiles que iluminaban sus talleres en invierno. Ese parot, vestido a la manera de los espantapájaros de la huerta, era el que se echaba al fuego para celebrar que los días empezaban a alargarse, en coincidencia con las fechas en que festejaban a su santo patrón. No obstante, la documentación conservada en el Gremio de Carpinteros, si bien cita tan señalada festividad religiosa, no hace ninguna mención de la construcción de fallas en su víspera. Por eso, y aunque parezca evidente el protagonismo de los carpinteros en la construcción de los catafalcos, otras teorías invitan a suponer que el origen de las fallas es muy anterior, y que incluso podría rastrearse, como ocurre con muchos festivales ígnicos de la Europa rural, en antiguas fiestas paganas que celebraban con hogueras los solsticios y equinoccios, y sobre las que la festividad de San José se acomodó sincréticamente. Y aún otras teorías emparentan esa tradición con una cultura carnavalesca medieval de la que ya sólo quedaba un pálido reflejo cuando las fallas comenzaron a consolidarse. Hay, desde luego, un aire de familia evidente entre ese realismo grotesco en declive, tan estudiado por Mijail Bajtin, y una festividad cuyo punto culminante consistía en arrojar al fuego a algún vecino en efigie, aprovechando las tradicionales hogueras que se prendían por doquier para simbolizar la renovación que traía consigo la primavera. Conexión reforzada por lo que el propio Bajtin aseguraba sobre el sistema de imágenes de la fiesta popular, en el que la muerte era sucedida por la resurrección, por el año nuevo (como ocurre hoy, por ejemplo, en la ciudad de La Plata, en $\operatorname{Argentina}^{1}$ ), o por la primavera (como sucede con las fallas de Valencia), y en cuya ritualización "los espantapájaros festivos" simbolizaban a un rey-bufón "elegido por todo el pueblo, y escarnecido por el pueblo mismo; injuriado y expulsado al concluir su reinado, del mismo modo que todavía se escarnece, golpea, despedaza y quema o ahoga el muñeco del carnaval que encarna el invierno desaparecido o el año viejo". ${ }^{2}$ Desde ese punto de vista, bien podrían entenderse los ninots falleros como una actualización de esas "ejecuciones de farsa" que igualmente entroncan con la arraigada costumbre, en la Valencia del siglo XIX, de colgar en los balcones, el jueves de Cuaresma, monigotes a los cuales no es difícil suponer un trasfondo satírico.

Sin contradecir ninguno de esos tres supuestos orígenes, las fallas son, pues, una práctica colectiva nacida de la cultura popular (es decir, al margen de la cultura oficial), que depurada de sus elementos más groseros y subversivos poco a poco fue transformándose en reclamo turístico. A ese respecto, dice Gil-Manuel Hernàndez i Marti ${ }^{3}$, que, ante el imparable auge a mediados del siglo XIX de las fallas satíricas en detrimento de las hogueras, con especial predominio de la crítica política (entendida como "violencia simbólica"), y del carácter vecinal y erótico (como bien demuestran los llibrets de Josep Bernat i Baldoví o Blai Bellver), las autoridades pasaron de la vigilancia al castigo mediante la censura y las subidas de impuestos a las plantàs. Luego, el liberalismo ilustrado, consciente de que esa no era la mejor vía para eliminar las costumbres del pueblo, decidió sustituir la represión por una "reconversión esteticista" que acabó por imponerse en los primeros decenios del siglo XX a través, por ejemplo, de la institucionalización de premios a las fallas más artísticas, lo que decantó la profesionalización de sus futuros actores hacia una caricaturización más amable, de rasgos más académicos, y un marcado carácter local e identitario, que acentuó durante el franquismo la tendencia hacia el barroquismo y la monumentalidad espectacular que aún hoy caracterizan a las fallas.

En ese sentido, John Storey afirmaba que, mientras que en la cúspide de la jerarquía del gusto estaba la "pura" mirada estética ("una invención histórica"), poniendo el énfasis en la forma por encima de la función, la "estética popular" dio la vuelta a este énfasis, al subordinar la forma a la función. Consecuentemente, añadía Storey, la alta cultura tiene más que ver con "la contemplación" y "la representación", y la cultura popular con "Ia actuación" y "lo que se representa".

$Y$, ¿qué es lo que se representa en una falla? Para contestar a esa pregunta habrá que admitir primero que las fallas podrán variar de estilos y formas, materiales y modos de hacer, según las modas o los avances técnológicos de los que se sirvan sus artífices, y todo ello sin dejar de ser fallas, pero si abandonasen su vertiente jocosa y satírica dejarían de ser lo que siempre han sido. Por tanto, lo que se representa en una falla, desde siempre, es la realidad degradada de lo cómico, esa categoría estética ligada, según Aristóteles, a la imitación de lo ridículo, una modalidad de lo feo que no causa dolor ni compasión, sino hilaridad.

Ahora bien: la diversión que procura un fantoche al transgredir cualquier norma sin importancia induce a pensar que la risa de lo cómico celebra la transgresión pueril sin peligro alguno para nosotros, ya que el transgresor, y por tanto quien recibirá el castigo, es otro. Por eso, decía Umberto Eco, lo cómico no pone en cuestión las normas establecidas ni las reglas sociales comúnmente aceptadas, sino que, por el contrario, las reafirman, e incluso las oculta, presentándolas como indiscutibles. Pero existe, decía Eco también, otro tipo de humor que sí pone en evidencia el sinsentido de esas normas dominantes, haciendo que, al mismo tiempo que nos reímos, podamos preguntarnos por qué, o de qué, nos estamos riendo. Y ese es un humor propiamente satírico, el que no bloquea el pensamiento crítico, sino que lo estimula bajo un fondo de desasosiego que nos hace dudar. ${ }^{5}$

Desde ese punto de vista resulta evidente que lo cómico y el carnaval no son hoy transgresiones consentidas en el tiempo, como sucedía antiguamente, sino en el espacio: limitadas a ciertos lugares, ciertas calles, ciertos canales de televisión... Y como en un mundo de transgresión continua nada puede ser ya objeto de parodia salvo la transgresión misma, entonces las fallas podrían convertirse en vehículos perfectos con los que explorar paródicamente el potencial metafórico y asociativo de la sintaxis gramatical de los media. 
Partiendo de ese presupuesto, la falla infantil que resultó de aquél encargo de 2013, titulada Desplumados, acabó siendo un árbol, plantado junto al parking de la ETS de Ingeniería de Edificación, sobre el que la crisis económica había causado estragos. Un par de buitres coronaban su copa esperando el momento adecuado para abalanzarse sobre su próxima víctima. Y un avestruz hacía como aquellos que prefieren no ver lo que ocurre a su alrededor. Por sus esqueléticas ramas se sucedían las colas de pájaros ante la oficina de empleo e hileras de enfermos a falta de médicos para tanto paciente, colegios abarrotados de polluelos que no cabían en sus aulas, nidos en venta aquí y allá, y familias enteras emigrando hacia árboles lejanos. Habíamos pensado que la única nota de color en aquella falla la tenían que poner los niños de la Comisión, con hojas recortadas previamente que pintarían de verde, en alusión a la esperanza de un futuro más justo para todos, pero lo cierto es que a esa tarea le dedicaron una sola tarde, que en seguida se aburrieron, y que fuimos nosotros los que acabamos pintando los cientos de "brotes verdes" que daban el color a la falla. En aquella ocasión contamos, además, con la ayuda para la construcción del árbol de dos becarios, Eloísa Martínez y Alberto Perdigón, y la colaboración de nuestro alumnado en la asignatura Escultura I para el recorte y pintado de los numerosos personajes.

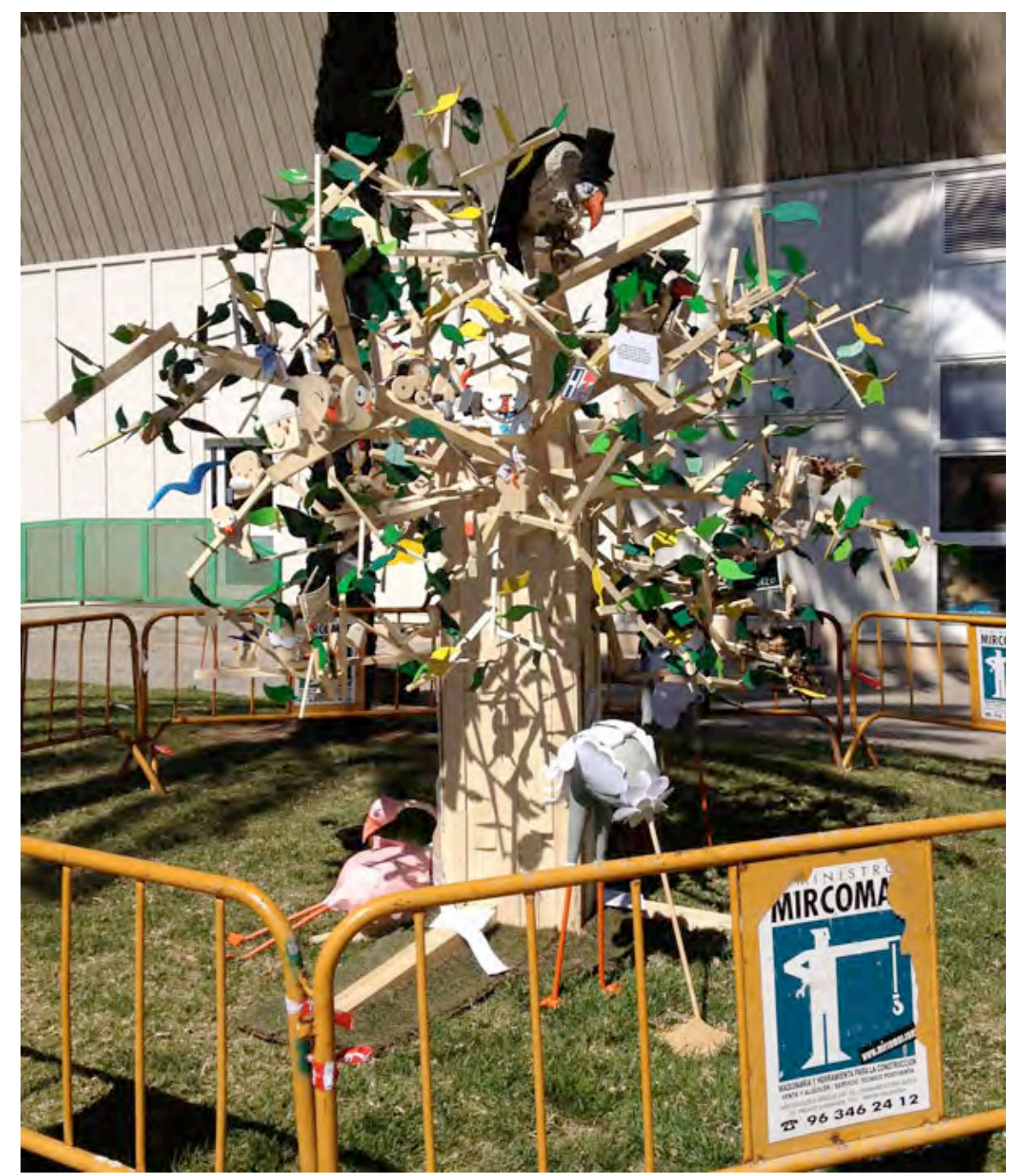

Con Desplumados obtuvimos el Primer Premio de Ingenio y Gracia de la Junta Central Fallera en nuestra sección, y la Comisión nos encargó entonces, encantados, dos fallas para el año siguiente, la infantil y la grande, con el mismo presupuesto que habíamos tenido para hacer la pequeña del año anterior.

Aceptado el reto, en Corbes de Nivell, la falla grande que hicimos para 2014 con la ayuda de Cristian Gil y Jordi Chornet, optamos por cubrir con cuatrocientas balas de paja, compradas a precio de saldo, una pirámide de madera de nueve metros de altura a cuya entrada colocamos la réplica de un ángel tallado por Mariano Benlliure para el panteón de la familia Moroder en el cementerio de Valencia. Tanto el ángel que invitaba a entrar en la pirámide, como la pirámide misma, medio mausoleo, medio monumento arqueológico, pretendían ser una alegoría de lo único que iguala a los seres humanos: la muerte. Así, entre el humor negro y el comentario social, contamos con la inestimable ayuda de Miguel Molina, DeCo Nascimento y los estudiantes de la asignatura Taller de 
Arte Sonoro, que se encargaron de instalar una serie de dispositivos que producían, en su interacción con el público, conciertos improvisados de música electroacústica, pasando la falla a llamarse Pirámide de Paja Pirofónica cuando participamos en el XVII festival Nits d'Aielo i Art organizado por Llorenç Barber y Montserrat Palacios.
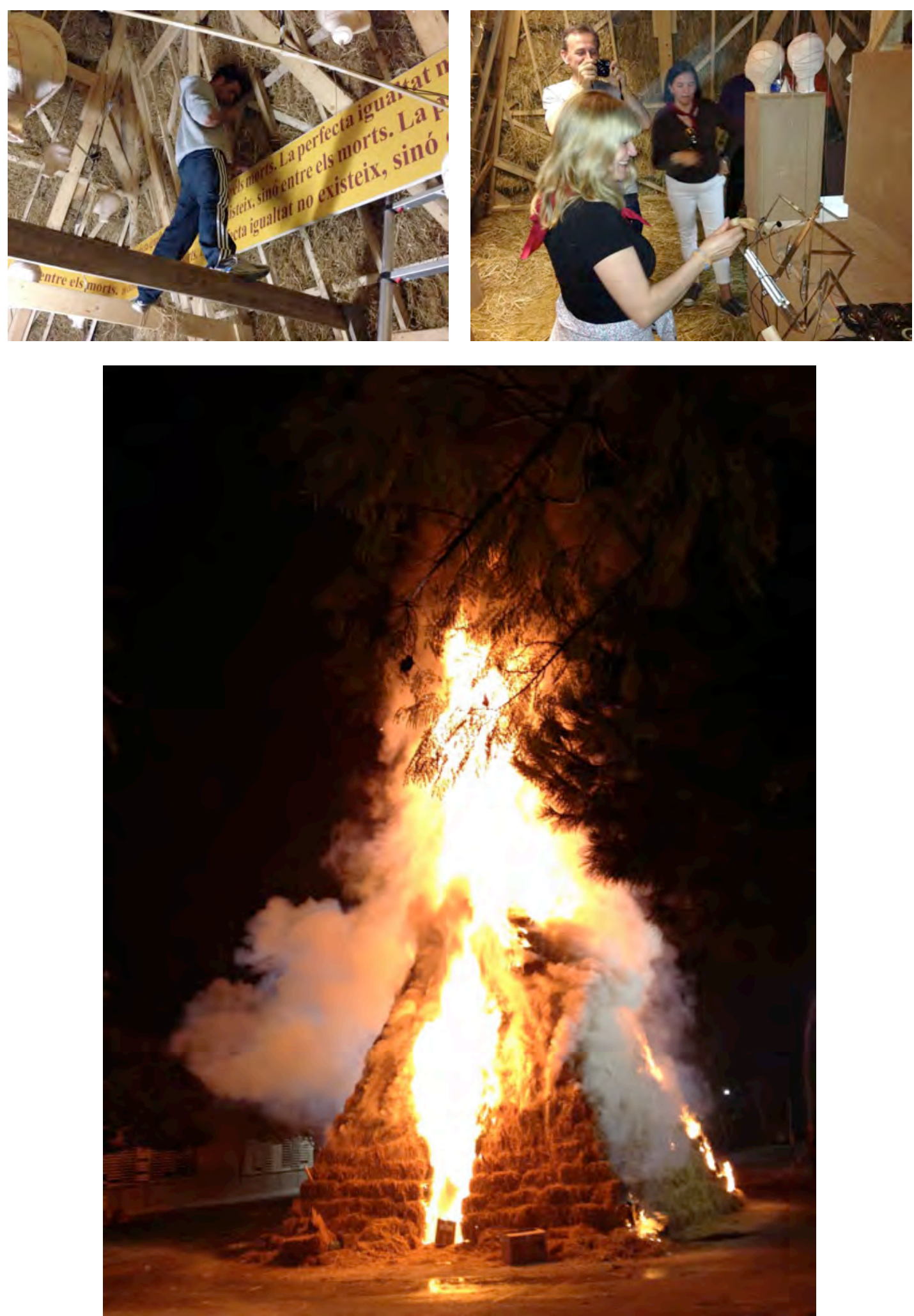
Por su parte, la falla infantil, titulada Falla Precocinada, parecía destinada a reflejar las penurias económicas que atravesábamos esos años. Pero para no repetirnos, la idea de partida -que era hacer la falla con los restos sobrantes de la grande-, tomó forma en un amontonamiento de maderos del que emergían decenas de pequeños tarugos antropomórficos que parecían construirse unos a otros y participar en la erección de la montaña de miseria de la que todos ellos salían. Consecuentes con esa premisa argumental, la elaboración de la falla contó con la colaboración de nuestros alumnos de la asignatura Escultura I. Y no deja de ser curioso que durante su realización se generase entre los estudiantes un interesante debate sobre la ironía de que ninguno de los personajes de la falla parecían ser conscientes de estar construyendo una pira cuyo destino era arder con ellos dentro. Como en la falla infantil del año anterior, la apariencia amable en los diseños de las figuras ocultaba una doble lectura con comentario envenenado.

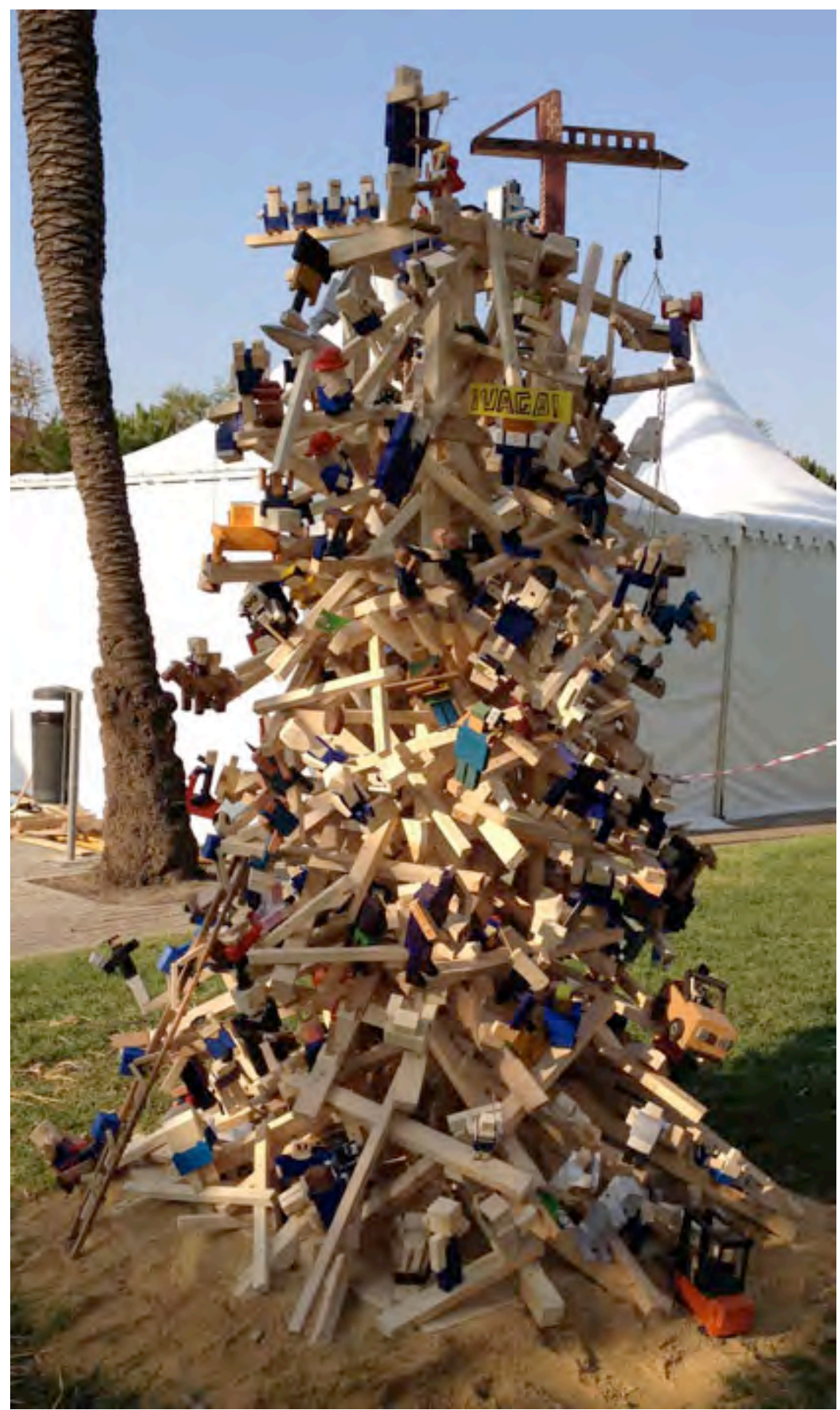


La falla Curvas de Nivel. Pirámide de paja pirofónica ganó el Primer Premio de Ingenio y Gracia en su sección, y la infantil el Segundo Premio de la suya. Y de nuevo la Comisión nos encargó sus dos fallas para el año siguiente.

Un año más perfilando ideas, realizando intermitentemente bocetos, maquetas, y equipando poco a poco, en otro espacio prestado, el taller improvisado en el que atender al nuevo encargo. En esta ocasión utilizábamos algo más de doscientos metros de tela, trescientos de cuerda, además de madera y cartón, para dar forma a dos cubos, uno de siete metros de lado, y el otro de dos y medio. El más grande, titulado Públicas virtudes, representaba un cubo de Rubik -del cual se cumplía en 2015 los cuarenta años de su invención-, reconvertido en una haima, ya que también ese año se cumplían los cuarenta años de la marcha verde y queríamos mostrar un mundo dividido por el muro de Marruecos y el conflicto saharaui. En ese sentido, también nuestro cubo estaba dividido en su diagonal por un muro, con la parte occidental a un lado, y la del llamado Tercer Mundo al otro. Como ocurría con la del año anterior, la estructura estaba pensada para adentrarse en ella, y contaba con efectos sonoros (explosiones que simulaban un campo minado) y una pared audio-visual (que emitía unos documentales que recordaban el conflicto al que la falla hacía referencia), de los que se hicieron cargo alumnos de Miguel Molina y Amparo Carbonell.

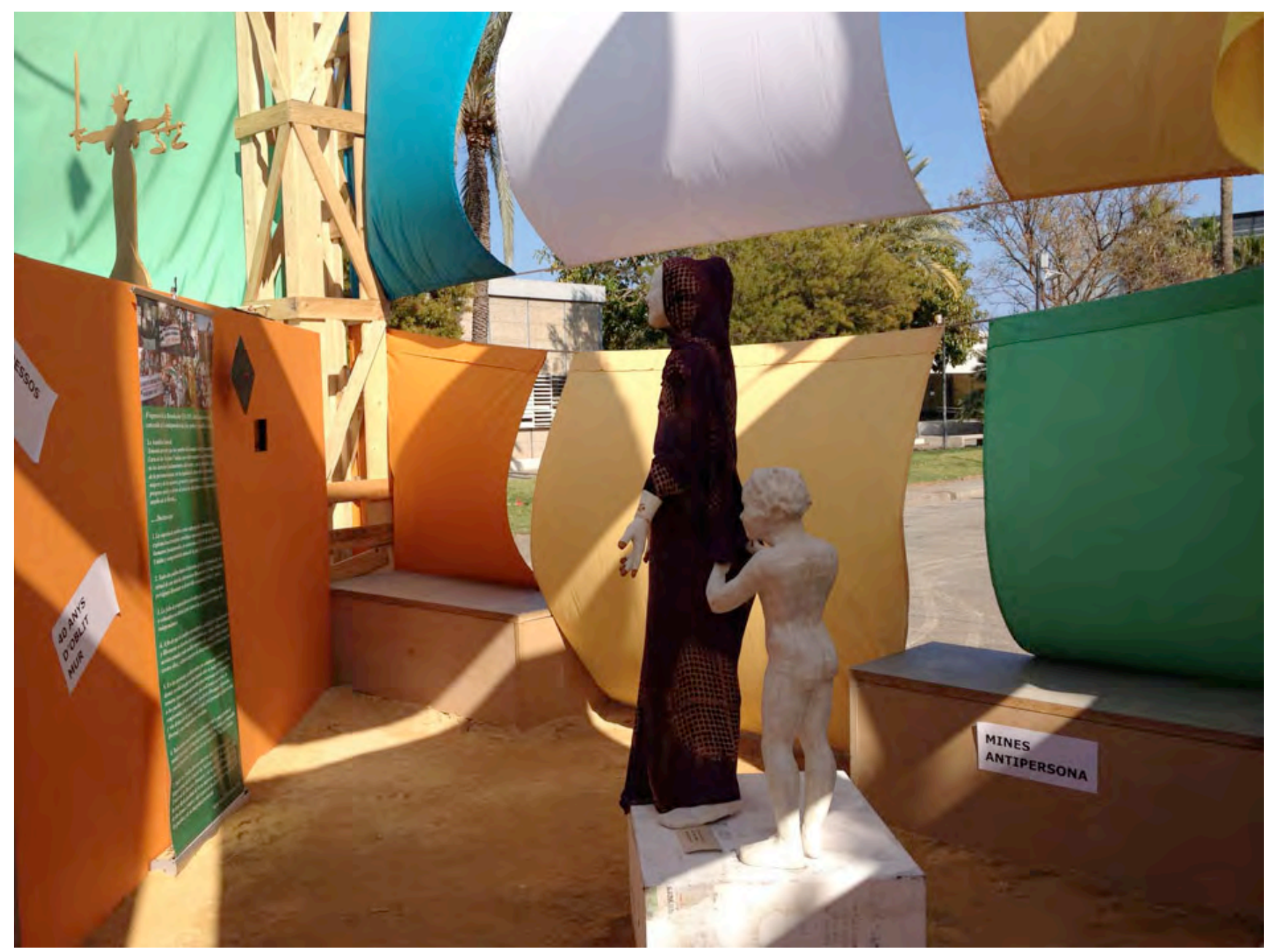

También en la falla infantil, titulada Cosas de niños, se podía entrar, aunque gateando, al no tener más entrada que una puerta a la altura de un gato. Su exterior era un cubo de Rubik que complementaba, a escala reducida, la falla grande. Pero su interior era otra cosa: un lugar en cuyas paredes podía descubrir, con ayuda de pequeñas linternas, cada cual a su propio ritmo, diversas escenas protagonizadas por conocidos personajes de los cuentos populares, del cine y los tebeos, de cartoons y videojuegos. En realidad, dichas paredes eran una pizarra sobre la que se invitaba, a quienes allí entrasen, a participar en la falla de una manera activa y lúdica, a que la hiciesen suya, escribiendo y dibujando con tizas de colores cuanto les dictase su imaginación regalarle al fuego. 


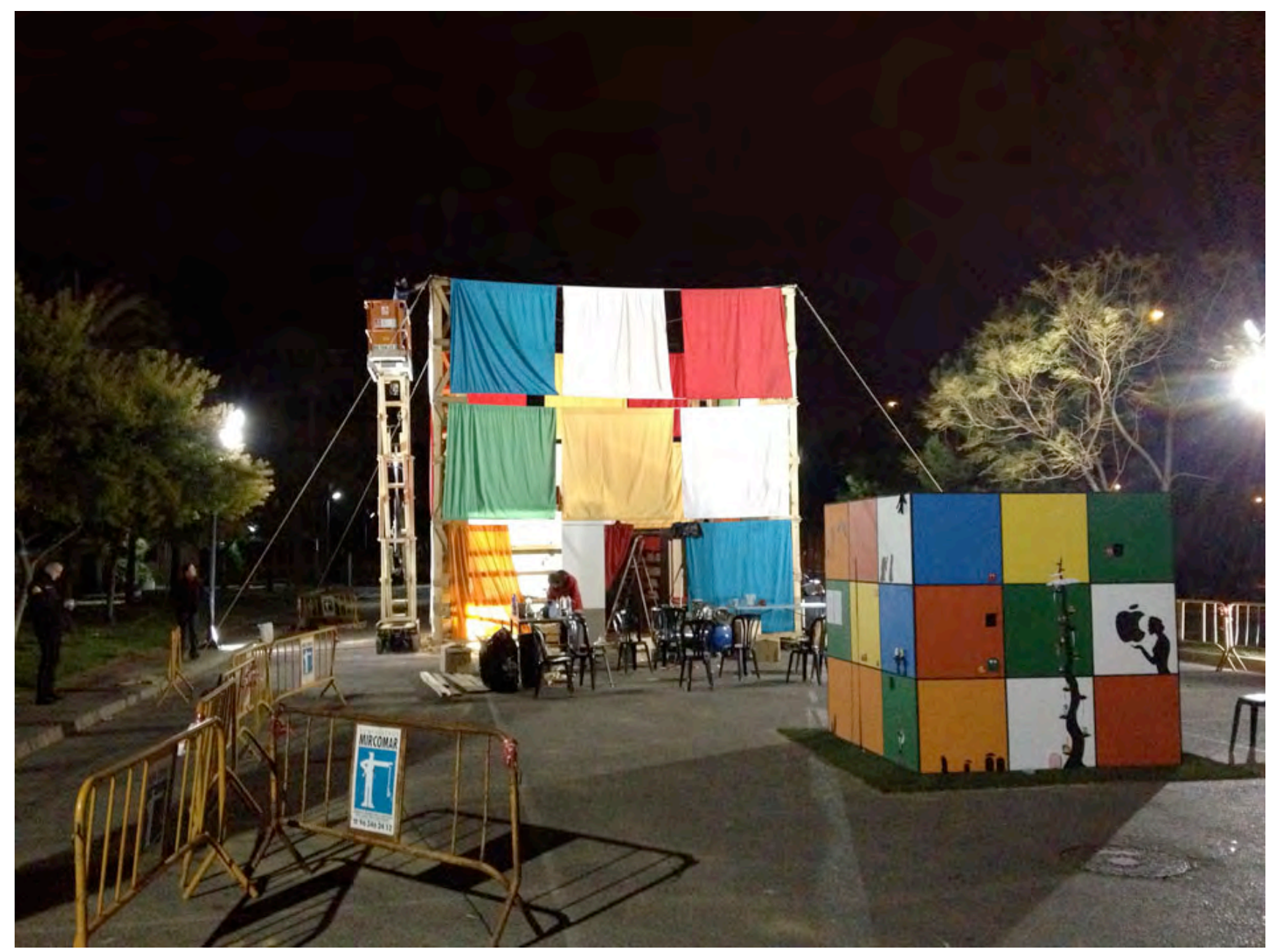

Cosas de niños ganó en 2015 el Primer Premio de Ingenio y Gracia, y Públicas virtudes el Segundo, cada una en su categoría, y ante la nueva oferta de hacer para 2016 las fallas de la misma Comisión llegó el momento de hacer recuento de las experiencias acumuladas. Aceptado el reto durante tres años, queremos insistir en que esos sucesivos encargos los asumimos, como profesores de escultura, por la oportunidad que suponía introducir a nuestro alumnado en las muy diversas técnicas que permite practicar el contacto con los materiales y los procesos constructivos de una falla. El resultado de cuanto hayamos hecho fue, en ese sentido, fruto de un trabajo colectivo, y nunca hemos ocultado nuestro agradecimiento a todas las personas (alumnos, pero también compañeros, profesores, artistas y amigos), que participaron en su realización. En todo caso, desde el principio tuvimos claro que no podíamos hacer una falla al uso, tanto por el escaso presupuesto como por el tiempo del que disponíamos. Ambos nos dedicamos a la docencia, a la investigación, y a actividades de gestión que no podemos desatender. Y aunque no debería hacer falta, hay que decirlo: hacer una falla, idearla, encontrar los materiales adecuados, experimentar con sus propiedades para sacarles el máximo rendimiento, además del trabajo que supone coordinar la colaboración de toda la gente a la que involucramos en cada proyecto, de un modo u otro, conlleva un año. Y por mucha ayuda con la que hayamos contado, la responsabilidad última de plantar las fallas y rematarlas sin percances, así como la de hacer entender nuestras propuestas a los falleros, que son quienes las financian, a fin de cuentas, era exclusivamente nuestra. Y lo cierto es que, al final, todo ese desgaste no se refleja curricularmente en ninguna parte. Como sabemos, la universidad, en los últimos años, obliga a investigar a todos sus miembros. Pero el inmenso trabajo que conlleva hacer una falla, al menos en la UPV, ni se contempla como investigación. Al parecer, investigar en nuestro campo es -al margen de que el trabajo que hemos realizado ya no existe, puesto que se quemó en su día-, ponerse a escribir informes, dando preferencia a los estudios analíticos y comparados frente a los puramente descriptivos.

No deja de ser motivo de reflexión, pues, el que se nos exija el doble de trabajo que a los demás investigadores en el campo de las Humanidades. En el Centre de Estudis Fallers, por ejemplo, y que sepamos, no se dedican a hacer fallas y luego se ponen a analizar o a comparar lo que han hecho, sino que estudian directamente las hechas por otros. En nuestro caso no ocurre lo mismo. Y aquí deberíamos entrar a considerar los criterios con los que se evalúa aquello que en la práctica artística se entiende por investigación, sólo que ese asunto nos haría pasar de las 3.000 palabras. Por eso nuestra aportación al presente congreso, a falta de futuros informes, se limitará a hacerles partícipes a ustedes de nuestro monumental cansancio. 


\section{FUENTES REFERENCIALES}

\footnotetext{
${ }^{1}$ Di Maria, Graciela - Albero, María. Los muñecos de fin de año: producciones artísticas efímeras platenses en espacios públicos. Artículo publicado en el II Congreso Iberoamericano de Investigación Artística y Proyectual en las V Jornadas de Investigación en Disciplinas Artísticas y Proyectuales, UNLP, año 2010

${ }^{2}$ Bajtin, Mijail. La cultura popular en la Edad Media y en el Renacimiento. El contexto de François Rabelais. Alianza, Madrid, 2003. Pág. 178

${ }^{3}$ Hernàndez i Martí, Gil-Manuel. Falles de València en blanc i negre. Edicions Tívoli (Alcoi)-Museu Valencià d’Etnologia-Diputació de València-Associació d’Estudis Fallers. Pág. 12

${ }^{4}$ Storey, J. Teoría cultural y cultura popular. Octaedro-EUB, 2002. Pág. 286

${ }^{5}$ Véase Eco, Umberto. Los marcos de la "libertad" cómica. En Ivanov, V.V. y Rector, Mónica. iCarnaval!. Fondo de Cultura Económica, México D.F., 1998
} 